\title{
Study on the dynamic characteristics of solidified silt under dynamic load
}

\author{
Shuo Jiang \\ South China University of Technology, Guangzhou, China \\ China Railway Guangzhou Group Co., Ltd, Guangzhou, China \\ E-mail:tou1479@foxmail.com
}

Received 18 July 2019; accepted 26 August 2019 DOI https://doi.org/10.21595/vp.2019.20912

Check for updates

Copyright (C) 2019 Shuo Jiang. This is an open access article distributed under the Creative Commons Attribution License, which permits unrestricted use, distribution, and reproduction in any medium, provided the original work is properly cited.

\begin{abstract}
The treatment and utilization of silt have always been a difficult problem in the field of engineering construction. Because of its high natural moisture content, low permeability and strength, rheological property and rich organic matter, the silt soil cannot be directly used in engineering practice. Under this background, in order to further explore the dynamic characteristics of solidified silt under dynamic load, a shallow mud along the coast of the Pearl River Delta in Guangdong Province was used as raw material, inorganic liquid solidifying agent and 32.5 ordinary Portland cement as solidifying agent. The dynamic characteristics of silt and solidified silt with age of 7 days and 28 days were studied by means of dynamic triaxial tests. The loaded samples were analyzed by SEM in laboratory. The experimental results show that the dynamic characteristics of the solidified silt soil under dynamic load are much better than that of the remoulded soil, and the solidification effect of the solidified silt soil with an age of 28 days is more obvious. The results can be applied to practical engineering practice.
\end{abstract}

Keywords: railway engineering, dynamic loads, silt soil, dynamic triaxial test, SEM.

\section{Introduction}

The pearl river delta in China has a developed water system with a large amount of deep silt. The presence of a large number of silt in the stratum need to conduct reinforcement treatment inevitably not only for railways, highways, bridges and subways, but for the construction of residential, office buildings and other projects. The traditional treatment methods of silt soft soil foundation are mainly consisted of riprap, compaction and silting, excavation and replacement [1]. However, these methods have many limitations in practical engineering application, which not only produce a lot of wastes, but also cause irreparable damage to natural resources due to engineering excavation. Therefore, how to deal with the characteristics of silt in engineering is particularly important.

At present, for the treatment of shallow silt, the methods such as improved soil filling and in situ curing can be mainly adopted [2]. Although the improved soil filling method has some advantages in price, but by considering the social costs such as abandoned land acquisition and earthwork transportation, the in-situ solidification treatment of silt has more advantages.

Therefore, in order to study the dynamic characteristics of silt soil after reinforcement under dynamic load, this paper, taking the shallow silt soil as the raw material from the coastal at Guangdong pearl river delta region, combining with inorganic liquid curing agent and 32.5 Portland cement as additives, and by using SDT - 10 computer control electro-hydraulic servo soil dynamic triaxial testing machine to carry out the indoor dynamic triaxial test, at the same time using scanning electron microscope to microscopic observation of the samples after test.

Generally, with the increase of load strength and duration, the strain of soil increases. However, under the action of cyclic dynamic load, the plastic deformation amplitude of soil has both an increasing tendency (hardening) and a decreasing tendency (softening). Secondly, dynamic responses of different soils under dynamic loads are also different [3]. Therefore, in order to obtain the dynamic characteristics of soil under dynamic load, we should not only analyze the 
relationship between the stress level of soil under dynamic load and the maximum strain, but also analyze the change law of cumulative deformation of soil under the action of changing cycle times [4].

In this experiment, the dynamic characteristics of undisturbed silt, solidified silt of different ages under the action of different stress levels and different cycles were analyzed, and the test samples after the action of different stress levels were observed by scanning electron microscope. Thus, the dynamic action rules of undisturbed silt and solidified silt at different ages under macro and micro conditions are established.

\section{Dynamic test of silt solidified soil}

\subsection{Experimental materials and preparation}

The physical and mechanical properties of silt are shown in Table 1. It can be seen from the table that silt has a high natural moisture content and is in a state of near saturation (saturation is greater than $98 \%$ ). Organic matter content in silt is $5.815 \%$, belong to organic matter soil. The results of quick shear test and unconsolidated and undrained triaxial test show that the shear strength of silt in this site is very small, almost with no strength. The liquid limit and plastic limit of the silt indicate that the silt is in a state of flow plasticity and has high compressibility.

Table 1. Physical and mechanical properties of silt

\begin{tabular}{|c|c|c|c|c|c|c|c|c|c|c|}
\hline $\begin{array}{c}\text { Natural } \\
\text { moisture } \\
\text { content } \\
(\%)\end{array}$ & $\begin{array}{c}\text { Natural } \\
\text { density } \\
\left(\mathrm{g} / \mathrm{cm}^{3}\right)\end{array}$ & $\begin{array}{c}\text { Natural } \\
\text { void } \\
\text { ratio }\end{array}$ & $\begin{array}{c}\text { Compression } \\
\text { modulus } \\
\left(\mathrm{mPa}^{-1}\right)\end{array}$ & $\begin{array}{c}\text { Compression } \\
\text { coefficient } \\
(\mathrm{mPa})\end{array}$ & $\begin{array}{c}\text { Liquid } \\
\text { limit }(\%)\end{array}$ & $\begin{array}{c}\text { Plastic } \\
\text { limit } \\
(\%)\end{array}$ & $\begin{array}{c}\text { Saturation } \\
(\%)\end{array}$ & $\begin{array}{c}\text { Organic } \\
(\%)\end{array}$ & $\begin{array}{c}\varphi \\
\left({ }^{\circ}\right)\end{array}$ & $\begin{array}{c}c \\
(\mathrm{kPa})\end{array}$ \\
\hline 58.58 & 1.632 & 1.5466 & 1.562 & 1.376 & 44.54 & 26.76 & 98.98 & 5.815 & 3.22 & 7.6 \\
\hline
\end{tabular}

Considering the natural structure of silt and the influence of soil disturbance on the test results, the soil sample was remolded before the test. During remolding, the moisture content of the sample at $30 \%$ of the optimal construction moisture content was selected. According to the Railway engineering geotechnical test code (TB 10102-2010), the operation procedure is carried out.

The silt used in the experiment was taken from shallow silt at the bottom of a reservoir in the pearl river delta region of Guangdong. In the sampling process, the soil depth of the silt is 0.5-3.0 m, and the lower part of the silt is the sand layer. The curing agent is a "Xiyang brand" F type liquid curing agent produced by Dalian Xinyang Waterproof Engineering group Co., Ltd. Cement is 32.5 ordinary Portland cement.

The size of prepared sample: diameter $39.1 \mathrm{~mm}$, height $80 \mathrm{~mm}$.

\subsection{Test schemes for different stress levels}

Under a certain consolidation confining pressure, the specimens stabilized after consolidation will cause additional deformation in the soil under the action of dynamic load. In this test, due to the great dynamic load amplitude in the vertical direction caused by the running of the railway train through the soil, the confining pressure was used to simulate the actual stress state between the natural soil in the lateral direction, and the sinusoidal wave load in the axial direction was used to simulate the dynamic response caused by the running of the railway train through the silt soil.

The study on the dynamic characteristics of soil mass under train load is determined by the reasonable simulation of traffic load by indoor tests. However, due to the different research emphases of indoor dynamic test in simplified simulation of traffic load, or due to the limitation of test conditions, its dynamic simulation and test scheme design are different. At present, the research results of dynamic stress field caused by traffic load show that the stress borne by soil body under traffic load varies. Therefore, the variation of confining pressure from $50-120 \mathrm{KPa}$ and the amplitude of axial load from 50-120 N are proposed in this test. In this paper, the confining 
pressure and dynamic load change at the same time, and the stress level generated under different confining pressure and dynamic load conditions is different. In this agreement, the maximum deviatoric stress value in a certain state is used to represent the stress level in this state.

The effect of railway train running on soil is closely related to loading frequency, drainage conditions, cycle times, axial load amplitude, confining pressure and other main factors. The frequency range of dynamic wave used in many related literatures is $0.1-10 \mathrm{~Hz}$, in which $1-2 \mathrm{~Hz}$ is the main frequency. In this study, it is proposed that all tests are carried out under the condition of frequency of $1 \mathrm{~Hz}$. In addition, under the long-term action of train load, the actual drainage is between complete drainage and no drainage. However, due to the uncertainty of the development of cumulative deformation under the condition of no drainage, the test under the condition of no drainage can better reflect the dynamic response of natural soil under dynamic load. Therefore, in order to guarantee the authenticity of the test, dynamic test in undrained conditions was used. Through the cycles and certainly change the size of the stress level test, thereby gaining undisturbed silt soil with different ages solidified mud soil stress level and the relationship between the maximum strain.

During the test, the axial load applied should be as close as possible to the vibration load generated by high-speed railway trains. The dynamic stress amplitude of this test is given as follows: $\sigma_{d}=0.26 \times P \times(1+a V)$. Where, $P$ is the static axle load $(\mathrm{kN})$ of locomotive and vehicle. $\alpha$ is the velocity coefficient. High-speed, seamless line, $a=0.003$. Quasi-high-speed, seamless line, $a=0.004$.

The maximum speed is $250 \mathrm{~km} / \mathrm{h}$, and the axle load is $23 \mathrm{t}$. Under the calculation of axial load amplitude: $23 \times 103 / 102.04 \times 0.26 \times(1 \times 0.004 \times 250)=111.348 \mathrm{kPa}$.

In order to eliminate interference, the test cycles in this experiment, it need to control cycles for 400 times and set the confining pressure from 50 to $120 \mathrm{KPa}$. The axial load amplitude varying from 50 to $120 \mathrm{~N}$ to simulate different speed of train set of dynamic load. The maximum strain change rule of solidified mud soil and undisturbed silt soil with different ages under different stress level conditions was discussed. Specific test control conditions are shown in Table 2.

Table 2. Different stress level test control conditions

\begin{tabular}{|c|c|c|c|c|}
\hline Confining pressure $(\mathrm{kPa})$ & Axial load amplitude $(\mathrm{N})$ & Frequency $(\mathrm{Hz})$ & Drainage condition & Loading times \\
\hline 50 & 50 & 1 & Undrained & 400 \\
\hline 60 & 60 & 1 & Undrained & 400 \\
\hline 70 & 70 & 1 & Undrained & 400 \\
\hline 80 & 80 & 1 & Undrained & 400 \\
\hline 90 & 90 & 1 & Undrained & 400 \\
\hline 100 & 100 & 1 & Undrained & 400 \\
\hline 110 & 110 & 1 & Undrained & 400 \\
\hline 120 & 120 & 1 & Undrained & 400 \\
\hline 120 & 120 & 1 & Undrained & 400 \\
\hline
\end{tabular}

\subsection{Test scheme for different cycle times}

Cycle number refers to the repeated action of load on soil in a certain period, which can be called cycle effect. Because the train tire runs back and forth on the railway, the dynamic load generated by it may also cause fatigue strength failure of the soil after repeated several times. Therefore, cycle number is also an important parameter affecting soil dynamic characteristics. In this test, by controlling the confining pressure of $50 \mathrm{KPa}$, the axial load amplitude of $50 \mathrm{~N}$, and the number of cycles from 100 to 1000, the change rule of cumulative strain between undisturbed silt and solidified soil of different ages under different cycle times was discussed. Specific test control conditions are shown in Table 3. 
Table 3. Test control conditions for different cycle times

\begin{tabular}{|c|c|c|c|c|}
\hline Confining pressure (kPa) & Axial load amplitude (N) & Frequency $(\mathrm{Hz})$ & Drainage condition & Loading times \\
\hline 50 & 50 & 1 & Undrained & 100 \\
\hline 50 & 50 & 1 & Undrained & 200 \\
\hline 50 & 50 & 1 & Undrained & 300 \\
\hline 50 & 50 & 1 & Undrained & 400 \\
\hline 50 & 50 & 1 & Undrained & 500 \\
\hline 50 & 50 & 1 & Undrained & 600 \\
\hline 50 & 50 & 1 & Undrained & 700 \\
\hline 50 & 50 & 1 & Undrained & 800 \\
\hline 50 & 50 & 1 & Undrained & 900 \\
\hline 50 & 50 & \multicolumn{2}{c}{} \\
\hline
\end{tabular}

\section{Different levels of stress}

The maximum strain test data of original silt, $7 \mathrm{~d}$ curable silt and $28 \mathrm{~d}$ curable silt at different stress levels are shown in Fig. 1. It is under the condition that the cycle times are 400 times, the confining pressure is from $50-120 \mathrm{KPa}$, and the axial load amplitude is from $50-120 \mathrm{~N}$.

Fig. 1 shows that the maximum strain of silt increases with the increase of stress level, and the maximum strain of undisturbed silt is much greater than that of solidified silt. By comparing the curable silt of different ages, the maximum strain of the curable silt of $28 \mathrm{~d}$ is also less than that of the curable silt of $7 \mathrm{~d}$. Therefore, the general variation law of the dynamic characteristics of silt under dynamic load can be obtained:

1. With the increase of confining pressure and axial pressure, the stress level will also increase; the maximum strain of silt increases with the increase of stress level.

2. By comparing the change curves of undisturbed silt and solidified silt at different ages, the maximum strain of silt with curing agent is far less than that with undisturbed silt.

3. Compared with $7 \mathrm{~d}$ curable silt and $28 \mathrm{~d}$ curable silt, soil with a phase of $28 \mathrm{~d}$ should be changed less; this indicates that the stiffness improvement of the curing silt at 28 days is more significant than that of the curing silt at 7 days.



Fig. 1. Maximum strain curve of silt under different stress levels

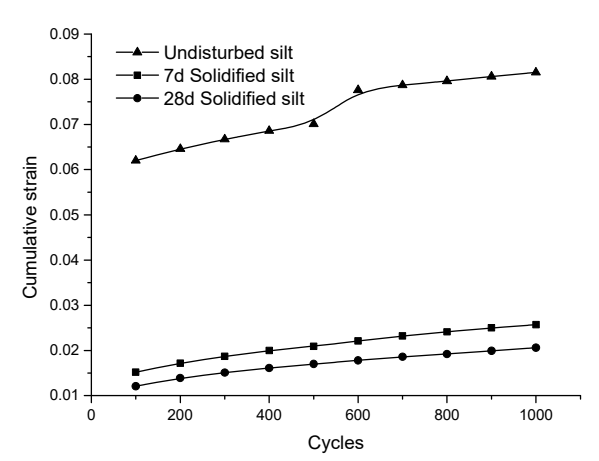

Fig. 2. Cumulative strain curve of silt under different cycles

\section{Different cycle times}

Set the confining pressure as $50 \mathrm{KPa}$, the axial load amplitude as $50 \mathrm{kN}$, and the cycle times from 100 to 1000 times. Fig. 2 is for the cycle times and cumulative strain test data of original silt, $7 \mathrm{~d}$ curable silt and $28 \mathrm{~d}$ curable silt.

Fig. 2 shows that the amplitude of confining pressure and axial load is constant, and the cumulative strain of silt increases with the increase of cycle times. But the accumulated strain of solidified silt is much smaller than that of undisturbed silt under the same condition. This indicates 
that the addition of curing agent improves the stiffness of silt.

Under the same test conditions, the dynamic responses of undisturbed silt and solidified silt at different ages are not the same under different cycles. With the increase of cycle times, the accumulated strain of soil increases. With the same vibration times, the accumulated strain of undisturbed silt is much higher than that of solidified silt, indicating that the dynamic stability of silt is improved after adding curing agent.

Under the action of the same cycle times, the cumulative strain of the $28 \mathrm{~d}$ solidified silt is all less than that of the $7 \mathrm{~d}$ solidified silt, indicating that with the development of time, the hydrolysis hydration reaction of cement and liquid curing agent have more obvious solidification effect on soil particles.

\section{Laboratory SEM microscopic test}

\subsection{Test principle and scheme}

Before the test, the interference of water on the test results was removed. Samples were taken from the undisturbed silt and the $7 \mathrm{~d}$ and $28 \mathrm{~d}$ solidified silt test blocks under the action of 400 cycles, confining pressure of $70 \mathrm{KPa}$ and axial load amplitude of $70 \mathrm{~N}$. After drying, the samples were placed on the observation table for observation. After the experiment, the size, shape and density of soil particles and hydration products of undisturbed silt and solidified silt at $7 \mathrm{~d}$ and $28 \mathrm{~d}$ were observed at multiples of $10 \mu \mathrm{m}$ and $1 \mu \mathrm{m}$. The internal relation between the difference of soil microstructure and its mechanical properties is analyzed.

\subsection{Sample legend observed in test}

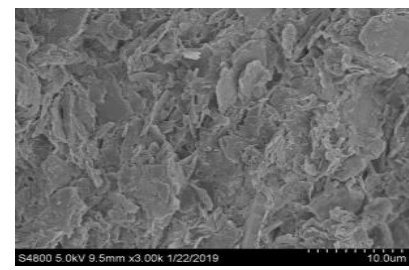

a) Undisturbed silt

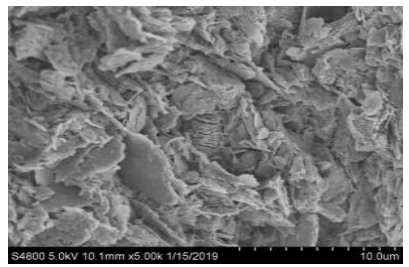

b) $7 \mathrm{~d}$ solidified soil

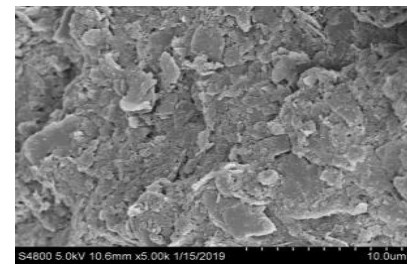

c) $28 \mathrm{~d}$ solidified soil

Fig. 3. $10 \mu \mathrm{m}$ solidified soil SEM picture

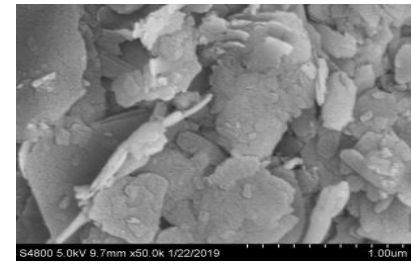

a) Undisturbed silt

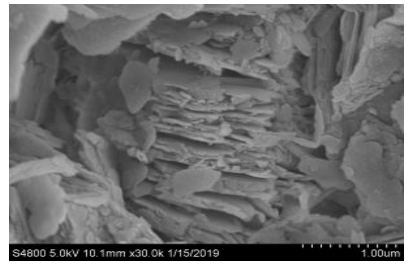

b) 7d solidified soil

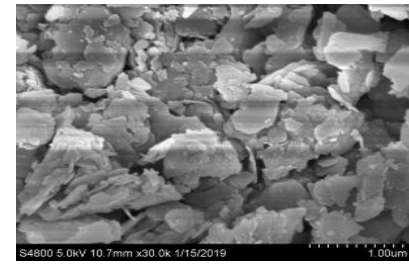

c) $28 \mathrm{~d}$ solidified soil

Fig. 4. $1 \mu \mathrm{m}$ solidified soil SEM picture

\subsection{Test results}

By observing Fig. 3(a), it can be found that the connection between undisturbed silt and soil is good, indicating that under the action of 400 cycles, $70 \mathrm{KPa}$ confining pressure and $70 \mathrm{~N}$ axial load, the soil becomes compact and the soil remains intact. Looking at Fig. 4(a), the particles in the soil are not evenly distributed and the connection between the soil particles is weak, indicating that there are large pores in the soil with low strength.

By observing Figs. 3(a) and 3(b), the surface texture of 7d solidified silt particles is clear and the dispersion is more uniform, indicating that under the action of the same dynamic strength, the 
mechanical properties of $7 \mathrm{~d}$ solidified silt are far better than the original silt. By comparing Figs. 4(a) and 4(b), it can be found that the pores between soil particles are significantly reduced, and the relationship between soil particles is close, indicating that the stiffness of $7 \mathrm{~d}$ solidified silt is higher than that of undisturbed silt. However, there are still many voids in $7 \mathrm{~d}$ solidified silt, indicating that curing agent has not played a good role in the $7 \mathrm{~d}$ curing period.

By observing Figs. 4(b) and 4(c), the soil particle density of $28 \mathrm{~d}$ solidified silt is better than that of $7 \mathrm{~d}$ solidified silt, indicating that under the same dynamic action, the improvement of the elastic modulus of $28 \mathrm{~d}$ solidified silt is much better than that of $7 \mathrm{~d}$ solidified silt. The distribution of soil particle crystals is more uniform, indicating that the curing agent has more obvious curing effect on soil particles with the increase of time.

By observing Fig. 3 and Fig. 4, the silt with curing agent shows completely different characteristics from the original silt, with the decrease of particle size and agglomeration of soil particles. The change in size and shape indicates that the curing agent has a chemical reaction with the silt after entering the soil, which improves the adhesion between the silt particles and the dispersion of the silt particles. As a result, the silt particle structure becomes denser, the stiffness of the internal structure of the silt is enhanced, and the elastic modulus of the silt is greatly improved. It has a good effect on the solidification of silt.

\section{Conclusions}

In this paper, based on the dynamic characteristics of the silt soil under the action of dynamic load caused by train, analyzes the different stress level and different cycles under the action of undisturbed silt soil and the change trend of different ages of the solidified mud soil strain. At the same time, through SEM test methods describe the structural morphology of silt soil, obtain the change rule of silt soil under dynamic action:

Under the action of different stress levels and different cycles, the deformation of the solidified silt is far less than that of the original silt, and the deformation of the solidified silt at the age of 28 days is also less than that of the solidified silt at 7 days.

Under the action of different stress levels and different cycles, the curing agent improves the dynamic stability of silt under dynamic action and improves the stiffness of silt.

Maximum strain of silt under different stress levels; the number of cycles is positively correlated with the cumulative deformation of silt.

The microscopic test of silt can well reflect the mechanical properties of the soil under the macroscopic state, indicating that the size, shape, surface characteristics of the soil microstructure and the spatial arrangement of elements determine its mechanical properties.

Based on the results of this study, we will explore the critical dynamic strength of undisturbed silt and solidified silt at different ages under different stress levels, analyze the improvement of soil strength by curing agent, enrich the theory of solidification mechanism of silt, and promote the application of solidification treatment of silt in railway engineering.

\section{References}

[1] Maher A., Douglas W. S., Yang D., Jafari F., Schaefer V. R. Cement deep soil mixing (CDSM) for solidification of soft estuarine sediments. Marine Georesources and Geotechnology, Vol. 25, 2007, p. 221-235.

[2] Galvín P., Romero A., Dominguez J. Vibrations induced by HST passage on ballast and non-ballast tracks. Soil Dynamics and Earthquake Engineering, Vol. 30, 2010, p. 862-873.

[3] Papadopoulos M., Van Beeumen R., François S., Degrande G., Lombaert G. Modal characteristics of structures considering dynamic soil-structure interaction effects. Soil Dynamics and Earthquake Engineering, Vol. 105, 2018, p. 114-118.

[4] Fan Q., Feng X., Weng W., Fan Y., Jiang Q. Unloading performances and stabilizing practices for columnar jointed basalt: a case study of Baihetan hydropower station. Journal of Rock Mechanics and Geotechnical Engineering, Vol. 9, 2017, p. 1041-1053. 